\title{
High serum Ephrin-B2 levels predict poor prognosis for patients with gastric cancer
}

\author{
WEN-JING YUE ${ }^{1,2}$, YI-PIN LIU ${ }^{2}$, MING LI $^{2}$, CHENG-XIA LIU ${ }^{3}$, SHAO-JIA MOU ${ }^{2}$, \\ QIAN-KUN LI ${ }^{2}$ and ZI-PING CHEN ${ }^{1}$ \\ ${ }^{1}$ Department of Gastroenterology, The Qianfoshan Hospital of Shandong University, Jinan, Shandong 250014; \\ ${ }^{2}$ Department of Gastroenterology, Yantai Affiliated Hospital of Binzhou Medical University, Yantai, Shandong 264003; \\ ${ }^{3}$ Department of Gastroenterology, Affiliated Hospital of Binzhou Medical University, Binzhou, Shandong 256603, P.R. China
}

Received December 12, 2017; Accepted May 31, 2018

DOI: $10.3892 / \mathrm{ol} .2018 .9202$

\begin{abstract}
Gastric cancer is an intractable disease with a poor prognosis and limited treatment options. Its treatment remains a major clinical challenge worldwide. Ephrin-B2 is upregulated and involved in tumor growth in various types of cancer. However, the association between ephrin-B2 and prognosis of gastric cancer, and the potential of ephrin-B2 as a therapeutic target remains unknown. The present study investigated ephrin-B2 as a prognostic factor and a therapeutic target for gastric cancer. Reverse transcription-quantitative polymerase chain reaction was performed to detect the protein expression level of ephrin-B2 in gastric cancer serum samples $(n=162)$ and healthy serum samples $(n=165)$. It was revealed that the protein expression level of ephrin-B2 was significantly upregulated in gastric cancer serum samples compared with the healthy samples. Ephrin-B2 protein expression was associated with tumor size $(\mathrm{P}<0.001)$, metastasis $(\mathrm{P}=0.02)$ and TNM stage $(\mathrm{P}=0.03)$, and was indicated to be an independent prognostic factor for gastric cancer. Furthermore, the Kaplan-Meier survival curve demonstrated that patients with high ephrin-B2 protein expression had shorter overall and progression-free survival rates than those with low ephrin-B2 protein expression. Ephrin-B2 protein expression was induced by small interfering RNA (siRNA) transfection of HGC27 and MKN-45 cells, significantly impeding cell viability and inducing apoptosis of HGC27 and MKN-45 cells compared with the respective negative control (NC) group. Thus, to the best of our knowledge, the present study indicates that ephrin-B2 functions as an oncogene in gastric cancer, and that serum ephrin-B2 level may be a promising non-invasive
\end{abstract}

Correspondence to: Professor Zi-Ping Chen, Department of Gastroenterology, The Qianfoshan Hospital of Shandong University, 16766 Jingshi Road, Jinan, Shandong 250014, P.R. China

E-mail: chenzizisdu@sina.com

Key words: ephrin-B2, gastric cancer, oncogene, therapeutic target, prognosis prognostic indicator, as well as a therapeutic target for gastric cancer.

\section{Introduction}

Gastric cancer is an intractable disease and due to its poor prognosis and limited treatment options, it remains a major clinical challenge worldwide. Ephrin-B2, a membrane-anchored ligand that serves a key role in controlling angiogenic and lymphangiogenic growth factors, is upregulated and involved in tumor growth in various types of cancer (1). For example, ephrin-B2 protein overexpression has been demonstrated to be associated with poor overall survival rates in patients with head and neck squamous cell carcinoma (2). Ephrin-B2 mRNA levels have been reported to increase significantly with clinical stage, and high ephrin-B2 protein expression predicted a high 24-month survival rate of patients with ovarian cancer (3). Ephrin-B2 expression has also been demonstrated to be upregulated in primary hepatocarcinoma, glioblastoma and uterine cervical cancer (4-6). These findings suggest that ephrin-B2 may be a prognostic indicator in numerous types of cancer.

Ephrin-B2 is also a promising therapeutic target for cancer treatment and mediates glioblastoma stem-like-cell perivascular invasion (7). Ephrin-B2-knockdown has been demonstrated to block tumor initiation and treatment of established tumors via ephrin-B2 antibodies, which suppress progression in human glioblastoma stem-like cell-derived orthotopic xenografts (7). Systemic administration of ephrin-B2 blocking antibody indicated a reduction in the number of blood and lymphatic vessels in xenograft mice, and a concomitant reduction in tumor growth (8). Silencing of ephrin-B2 by RNA interference has been demonstrated to inhibit proliferation, invasion, migration and angiogenesis and to induce apoptosis of colorectal cancer cells; a possible result of vascular endothelial growth factor (VEGF) and matric metallopeptidase 9 (MMP9) regulation (9).

The association between ephrin-B2 and gastric cancer prognosis and the potential of ephrin-B2 as a therapeutic target in gastric cancer treatment remains unknown. The present study investigated ephrin-B2 as a prognostic factor and therapeutic target for gastric cancer. 


\section{Materials and methods}

Collection of gastric cancer tissues and serum samples. Twenty gastric cancer tissues along with the matched healthy adjacent tissues were collected from patients at the Qianfoshan Hospital of Shandong University (Shandong, China) between April 2014 and April 2015. The serum samples were collected upon physical examination of healthy personnel (age median, 58 years; age range from 32-78 years; male/female: 80/85; $n=165$ ) and patients with gastric cancer (age median, 55 years; age range from 30-75 years; male/female: 78/84; $n=162$ ) from Qianfoshan Hospital of Shandong University (Shandong, China) between March 2009 and April 2016. Subjects with any other types of cancer, diabetes, cardiovascular and cerebrovascular diseases were excluded. Medical records of patients with gastric cancer with clinical Tumor-Node-Metastasis (TNM) staging and survival information were collected. The basic demographic characteristics and clinical features of the gastric cancer cases and heathy controls are presented in Table I. Overall survival (OS) is defined as the time from the date of pathological diagnosis to the date of mortality from any cause. Progression-free survival (PFS) is defined as the time from the date of pathological diagnosis to the date of the disease progression or mortality, if no progression was identified. All subjects provided written informed consent to participate in the present study. This project was approved by the Ethics Committee of The Qianfoshan Hospital, Shandong University (Shandong, China).

Cell lines and cell transfection. The gastric cancer cell lines, HGC27 and MKN-45, were obtained from the Cell Bank of the Chinese Academy of Sciences (Shanghai, China). Cells were grown routinely in RPMI-1640 medium (Invitrogen; Thermo Fisher Scientific, Inc., Waltham, MA, USA) supplemented with $10 \%$ foetal bovine serum (Gibco; Thermo Fisher Scientific, Inc.) and cultured in a $37^{\circ} \mathrm{C}$ with $5 \% \mathrm{CO}_{2}$.

Knockdown of ephrin-B2 was achieved by transfection of lentiviruses containing ephrin-B2 small interfering RNA (GeneCopoecia, Guangzhou, China; sequence: CCGGTC TACATCAAATGGGTCTTTGCTCGAGCAAAGACCCAT TTGATGTAGATTTTTG). The cells transfected with empty lentivirus were used as control. Cells were plated in 6 replicate wells in 96-well plates and cultured for $12 \mathrm{~h}$. Cells were then transfected with the lentivirus (multiplicity of infection=10) using Lipofectamine ${ }^{\circledR} 2000$ (Invitrogen; Thermo Fisher Scientific, Inc.) for $48 \mathrm{~h}$ according to the manufacturer's protocol. Transfected cells were used in subsequent assays.

Immunohistochemical (IHC) staining. The human tissues were fixed in $4 \%$ paraformaldehyde for $48 \mathrm{~h}$ at room temperature and paraffin-embedded. Tumor sections were cut into $4-\mu \mathrm{m}$ thick sections. The slides were regularly deparaffinised and dehydrated. Slides were treated with citric acid buffer ( $\mathrm{pH} 6.0$ ) in a microwave oven (500 W, $12 \mathrm{~min}$ ). Subsequent to cooling, the slices were blocked by normal goat serum (Wuhan Boster Biological Technology, Ltd., Wuhan, China), and incubated with a primary rabbit polyclonal anti-ephrin-B2 antibody (cat. no. ab131536; 1:100 dilution; Abcam, Cambridge, UK) overnight at $4^{\circ} \mathrm{C}$. The sections were then washed with PBS and incubated with an Goat Anti-Rabbit IgG (Biotin) (cat. no. ab6720; 1:2,000 dilution; Abcam) for $2 \mathrm{~h}$ at $37^{\circ} \mathrm{C}$ and washed by PBS. The slides were stained by using DAB Detection kit (Maxim, Xiamen, China) according to manufacturer's protocol. Finally, the sections were counterstained with $1 \%$ hematoxylin for $3 \mathrm{~min}$ at $45^{\circ} \mathrm{C}$. The IHC images were obtained at x 20 magnification under a light microscope (clipse Ni-E, Nikon, Japan). The quantification of positive signalling was performed by ImageJ (National Institutes of Health, Bethesda, MA, USA). The data of ephrin-B2-positive staining was analyzed in 8 fields of view and the data was averaged to produce a single value per subject.

Reverse transcription-quantitative polymerase chain reaction (RT-qPCR). TRizol reagent (Invitrogen; Thermo Fisher Scientific, Inc.) was used to extract total RNA from HGC27 and MKN-45 cells following lentiviral transfection. ABScript II cDNA First-Strand Synthesis kit (cat. no. RK20400; ABclonal Biotechnology Co., Ltd, Wuhan, China) was used for reverse transcription, according to the manufacturer's protocol. The expression of ephrin-B2 was measured by SsoFast EvaGreen supermix [cat. no. 1725201; Bio-Rad Laboratories (Shanghai) Co., Ltd. Shanghai, China], according to the manufacturer's protocol. Expression of $\beta$-actin was used as an endogenous control. The following primers were used: Ephrin-B2, forward, 5'-GCTGGGGTGTTTTGATGGTTT-3', reverse, 5'-AGTGCA TCTGTCTGCTTGGT-3'; $\beta$-actin, forward, 5'-GCCCTATAA AACCCAGCGGC-3', reverse, 5'-TCGATGGGGTACTTC AGGGT-3'. The primers were synthesized by Sangon Co. Ltd. (Shanghai, China). RT-qPCR was performed with the following thermocycling conditions: $95.0^{\circ} \mathrm{C}$ for $3 \mathrm{~min}$, and 39 cycles of $95.0^{\circ} \mathrm{C}$ for $10 \mathrm{sec}$ and $60^{\circ} \mathrm{C}$ for $30 \mathrm{sec}$.

GenElute Plasma/Serum RNA Purification Midi kit (cat no. RNB600; Merck KGaA, Darmstadt, Germany) was used to isolate RNA from $1.5 \mathrm{ml}$ serum per subject, according to the manufacturer's protocol. The quality and quantity of RNA was evaluated using NanoDrop 2000 (Thermo Fisher Scientific, Inc.). The RNA yield from these serum sample was $\sim 50 \mathrm{ng} / \mathrm{ml}$. The average absorbance ratio at $260 / 280 \mathrm{~nm}$ was $\sim 1.93$. A total of fifty ng RNA was reverse transcribed using a cDNA ABScript II cDNA First-Strand Synthesis kit (cat. no. RK20400, ABclonal Biotechnology Co., Ltd, Wuhan, China) according to the manufacturer's protocol The RT-PCR data was analysed by using $2^{-\Delta \Delta \mathrm{Cq}}$ method (10).

Cell Counting kit-8 proliferation assay (CCK-8). HCG27 and MKN45 cells proliferation rates were measured using CCK-8 (Beyotime Institute of Biotechnology, Hangzhou, China) following Ephrin B2 knockdown. Cells were seeded at $0.5 \times 10^{4}$ cells per well in a 96-well plate for $24 \mathrm{~h}$, and further incubated for 24,48 or $72 \mathrm{~h}$. A total of $10 \mu \mathrm{l} \mathrm{CCK}-8$ reagent was added to each well $1 \mathrm{~h}$ prior to the endpoint of incubation. The optical density value per well was determined by a microplate reader at a wavelength of $570 \mathrm{~nm}$. The experiments were repeated three times. Triplicate wells were used in each group.

Flow cytometry. An Annexin V-FITC/PI Apoptosis Detection kit (cat no. 40302ES50, Yeasen, Shanghai, China; http://www.yeasen.com/) was used for analysis of apoptosis. HGC27 and MKN-45 cells were harvested and washed twice 
Table I. Basic demographic characteristics and clinical features of the patients with gastric cancer and healthy controls.

\begin{tabular}{|c|c|c|c|c|}
\hline Characteristics & $\begin{array}{l}\text { Gastric cancer } \\
\text { tissue }(n=20)\end{array}$ & $\begin{array}{l}\text { Serum from patients } \\
\text { with gastric cancer }(n=162)\end{array}$ & $\begin{array}{l}\text { Heathy control } \\
\text { serum }(n=165)\end{array}$ & $\begin{array}{l}\text { P-value (patient vs. } \\
\text { healthy serum) }\end{array}$ \\
\hline Age, years (mean \pm standard deviation) & $57.4 \pm 11.2$ & $56.6 \pm 12.3$ & $55.6 \pm 8.4$ & 0.562 \\
\hline \multicolumn{5}{|l|}{ Sex } \\
\hline Male & 12 & 78 & 80 & 0.951 \\
\hline Female & 8 & 84 & 85 & \\
\hline \multicolumn{5}{|l|}{ Tumor size } \\
\hline$<5 \mathrm{~cm}$ & 7 & 78 & & \\
\hline$\geq 5 \mathrm{~cm}$ & 13 & 84 & & \\
\hline \multicolumn{5}{|l|}{ Distant metastasis } \\
\hline No & 7 & 74 & & \\
\hline Yes & 13 & 88 & & \\
\hline \multicolumn{5}{|l|}{ Tumor-Node-Metastasis } \\
\hline I-II & 5 & 69 & & \\
\hline III-IV & 15 & 93 & & \\
\hline
\end{tabular}

with PBS. A total of $2 \times 10^{5}$ cells were resuspended in $500 \mu 1$ binding buffer from the kit. A total of $10 \mu \mathrm{l}$ Annexin V-FITC and $10 \mu \mathrm{l}$ propidium iodide (PI) were added and mixed. After $15 \mathrm{~min}$ incubation, the cells were analyzed using a flow cytometer (BD Biosciences, San Jose, CA, USA) according to the manufacturer's protocol. The experiments were repeated three times. FlowJo (version 10.4.2, FlowJo LLC, Ashland, OR, USA) was used to analyse the apoptotic rate.

Statistical analysis. All data from three independent experiments were expressed as the mean \pm standard deviation and processed using SPSS 17.0 statistical software (SPSS Inc., Chicago, IL, USA). The overall survival rate estimates were calculated using the Kaplan-Meier method with the log-rank test. The clinical association between ephrin-B2 expression and clinicopathological variables in patients with gastric cancer was evaluated by the $\chi^{2}$ test. The difference between two groups was calculated by Student's t-test and the difference between multiple groups were determined using a one-way analysis of variance with Tukey's post-hoc test. $\mathrm{P}<0.05$ was considered to indicate a statistically significant difference. In addition, factors that could predict the prognosis of patients with gastric cancer were investigated by univariate and multivariate analyses.

\section{Results}

Ephrin-B2 expression is upregulated in gastric cancer tissues and serum samples. IHC staining was performed to measure the protein expression level of ephrin-B2 in gastric cancer tissues $(n=20)$ and the matched healthy adjacent tissues. Ephrin-B2 was expressed in the cytoplasm of gastric cancer cells (Fig. 1). Ephrin-B2 expression was significantly increased in gastric cancer tissues compared with adjacent healthy control tissues (Fig. 1). In addition, RT-qPCR was performed to detect the protein expression level of ephrin-B2 in an independent cohort, including gastric cancer serum samples $(n=162)$ and healthy serum samples $(n=165)$. The expression of ephrin-B2 was revealed to be significantly upregulated in gastric cancer serum samples compared with the adjacent healthy samples (Fig. 2A), and the ephrin-B2 protein expression level was higher in serum from patients with TNM stage III-IV than TNM stage I-II disease (Fig. 2B), suggesting an association of ephrin-B2 with gastric cancer development.

Ephrin-B2 is associated with clinicopathoclinical features of patients with gastric cancer. The cases of gastric cancer were divided into high and low ephrin-B2 protein expression groups, according to the mean mRNA expression value. It was revealed that ephrin-B2 protein expression was associated with tumor size $(\mathrm{P}<0.001)$, metastasis $(\mathrm{P}=0.02)$ and TNM stage $(\mathrm{P}=0.03)$ (Table II). Univariate analysis indicated that the serum ephrin-B2 protein expression level $(\mathrm{P}=0.02)$, as well as tumor size $(\mathrm{P}=0.01)$, distant metastasis $(\mathrm{P}=0.02)$ and TNM stage $(\mathrm{P}=0.03)$ were significantly associated with prognosis (Table III). Multivariate analysis indicated that the serum ephrin-B2 protein expression level $(\mathrm{P}=0.01)$, tumor size $(\mathrm{P}=0.01)$, distant metastasis $(\mathrm{P}=0.03)$ and $\mathrm{TNM}$ stage $(\mathrm{P}=0.02)$ were independent factors for predicting the prognosis of patients with gastric cancer (Table IV).

High serum ephrin-B2 levels predict short overall and progression-free survival rates for patients with gastric cancer. The association between serum ephrin-B2 levels and survival time was analyzed in patients with gastric cancer. The Kaplan-Meier survival curve revealed that patients with high ephrin-B2 protein expression had shorter overall survival rates than those with low ephrin-B2 protein expression (Fig. 3A). It was also revealed that patients with low serum ephrin-B2 had longer progression-free survival times than those with high ephrin-B2 levels (Fig. 3B). Thus, the results suggest that ephrin-B2 served a role in the development of gastric cancer. 
A

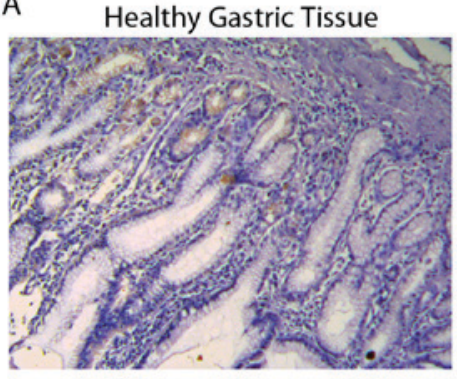

Gastric Cancer

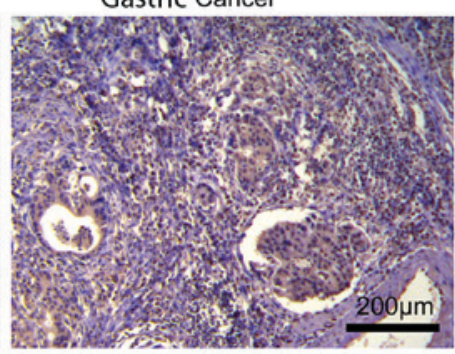

B

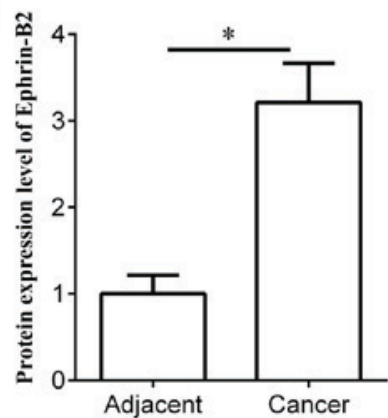

Figure 1. (A) Immunohistochemistry staining of ephrin-B2 in gastric cancer tissues and matched adjacent healthy tissues (n=20). (B) Quantification of the protein expression level of ephrin-B2 relative to gastric cancer tissues compared with matched adjacent control tissues (" $\mathrm{P}<0.05)$.
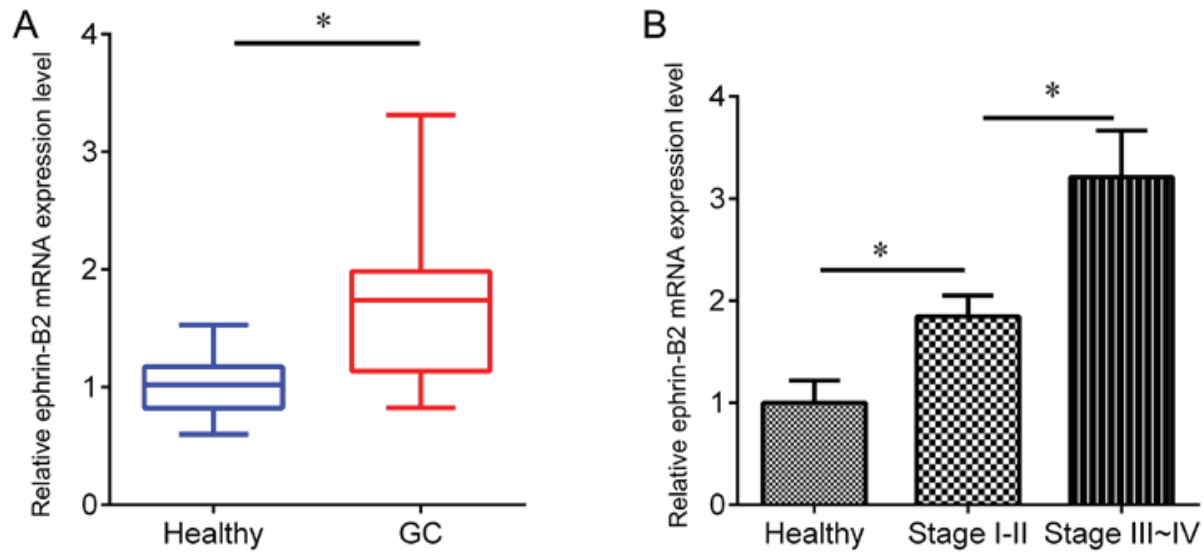

Figure 2. The expression of ephrin-B2 in serum samples. (A) RT-qPCR was performed to measure the expression of ephrin-B2 in serum samples from the gastric cancer group $(\mathrm{n}=162)$ and the healthy control group $(\mathrm{n}=165)$. (B) The protein expression level of ephrin-B2 in the healthy control group compared with patients with gastric cancer with stage I-II and stage III-IV disease ("P<0.05). RT-qPCR, reverse transcription-quantitative polymerase chain reaction; GC, gastric cancer.

Knockdown of ephrin-B2 by siRNA inhibits the proliferation and promotes apoptosis of gastric cancer cells. To investigate whether ephrin-B2 affected the proliferation of gastric cells, ephrin-B2 expression was knocked down by siRNA in HGC27 and MKN-45 cells (Fig. 4A). The corresponding effect on apoptosis was observed in a flow cytometry assay (the data was not shown), which indicated a significant induction of apoptosis by ephrin-B2-knockdown in HGC27 and MKN-45 cells compared with the NC group (Fig. 4B). Ephrin-B2-knockdown was indicated to significantly increase the viability of HGC27 and MKN-45 cells (Fig. 4C and D).

\section{Discussion}

In the present study, ephrin-B2 was indicated to be significantly upregulated in gastric cancer serum samples compared with the adjacent healthy samples. Ephrin-B2 was revealed to be associated with tumor size, metastasis and TNM stage. Furthermore, patients with gastric cancer with high ephrin-B2 protein expression were indicated to have shorter survival rates than those with low ephrin-B2 protein expression. Ephrin-B2 has been demonstrated to be upregulated in various types of cancer, including papillary thyroid carcinoma, ovarian cancer and glioblastoma (11). Protein expression of ephrin-B2 in arterial endothelium has been reported to be significantly increased in tumor sections of the kidney, the bladder and the prostate compared with non-tumor sections (12). An association has been identified between the protein expression level of ephrin-B2 in glioma tissues and the Karnofsky performance scale (KPS) score of patients with glioma. Positive protein expression rates of ephrin-B2 in glioma tissues were significantly higher in patients with low KPS scores (4). A significant increase in the mRNA expression levels of ephrin-B2 in ovarian cancer tissues with clinical stage has been identified in ovarian cancers. The 24-month survival rates of patients with high ephrin-B2 protein expression were indicated to be poor (3). In cervical cancer tissues, an increase of ephrin-B2 has been detected with disease advancement, based on clinical stage, lymph node metastasis, tumor size and poor patient prognoses (6). The aforementioned findings suggest that ephrin-B2 may be a prognostic indicator in several types of cancer. In the present study, it was reported that ephrin-B2 was significantly upregulated in gastric cancer serum samples compared with healthy samples. Taking into consideration the association of serum ephrin-B2 with tumor size, metastasis and TNM stage of gastric cancer, and the non-invasiveness of collecting serum samples, we speculate that ephrin-B2 function is a promising prognostic indicator for gastric cancer.

Ephrin-B2 regulates endothelial cell death (13), suggesting that ephrin-B2 is involved in angiogenesis (14). A previous 
Table II. Clinical association between serum ephrin-B2 levels and clinicopathological variables in gastric cancer.

\begin{tabular}{|c|c|c|c|}
\hline \multirow[b]{2}{*}{ Variable } & \multicolumn{2}{|c|}{ Serum ephrin-B2 } & \multirow[b]{2}{*}{ P-value ( $\chi^{2}$ test $)$} \\
\hline & Low expression $(\mathrm{n}=69)$ & High expression $(\mathrm{n}=93)$ & \\
\hline Age & & & 0.52 \\
\hline$<60$ & 33 & 50 & \\
\hline$\geq 60$ & 36 & 43 & \\
\hline Sex & & & 0.63 \\
\hline Male & 35 & 43 & \\
\hline Female & 34 & 50 & \\
\hline Tumor size & & & $<0.001$ \\
\hline$<5 \mathrm{~cm}$ & 46 & 32 & \\
\hline$\geq 5 \mathrm{~cm}$ & 23 & 61 & \\
\hline Distant metastasis & & & 0.02 \\
\hline No & 39 & 35 & \\
\hline Yes & 30 & 58 & \\
\hline Tumor-Node-Metastasis stage & & & 0.03 \\
\hline I-II & 36 & 33 & \\
\hline III-IV & 33 & 60 & \\
\hline
\end{tabular}

Table III. Univariate analysis of factors associated with gastric cancer.

\begin{tabular}{lcr}
\hline Variable & Hazard ratio $(95 \%$ confidence intervals) & P-value \\
\hline Age $(\geq 60 /<60)$ & $1.16(0.66-1.66)$ & 0.68 \\
Sex (male/female) & $1.07(0.67-1.47)$ & 0.72 \\
Tumor size $(\geq 5 \mathrm{~cm} /<5 \mathrm{~cm})$ & $2.34(2.24-2.44)$ & 0.01 \\
Distant metastasis $($ yes/no) & $4.21(3.81-4.61)$ & 0.02 \\
Tumor-Node-Metastasis stage (III-IV/I-II) & $2.55(2.35-2.75)$ & 0.03 \\
Serum ephrin-B2 levels (high/low) & $3.71(3.51-3.91)$ & 0.02 \\
\hline
\end{tabular}

Table IV. Multivariate analysis of potential independent prognostic factors of gastric cancer.

\begin{tabular}{lcr}
\hline Variable & Hazard ratio (95\% confluence intervals) & P-value \\
\hline Tumor size & $2.06(1.96-2.16)$ & 0.01 \\
Distant metastasis & $3.24(2.94-3.54)$ & 0.03 \\
Tumor-Node-Metastasis stage & $2.46(2.16-2.76)$ & 0.02 \\
Serum ephrin-B2 levels & $3.23(3.03-3.53)$ & 0.01 \\
\hline
\end{tabular}

study has reported that blocking ephrin-B2 with highly specific antibodies inhibits angiogenesis, lymphangiogenesis and tumor growth (8). Krusche et al (7) revealed that upregulation of the ephrin-B2 ligand in glioblastoma stem-like cells enabled perivascular migration through homotypic forward signaling. In human glioblastoma stem-like cell-derived orthotopic xenografts, ephrin-B2-knockdown was indicated to block tumor initiation. Furthermore, a combined treatment, involving an ephrin-B2-specific antibody, was indicated to have an additive activity that inhibited the migration and invasion of Kaposi sarcoma cells (15). An association between ephrin-B2 and chemoresistance has also been reported (16). Ephrin-B2 has been identified as a target gene of the gain-of-function mutant p53, which is responsible for chemoresistance (17). The mutant p53 complex has been reported to transcriptionally upregulate ephrin-B2 protein expression in response to DNA damage. Ephrin-B2-silencing has been demonstrated to restore chemosensitivity in mutant p53-harboring tumors, 

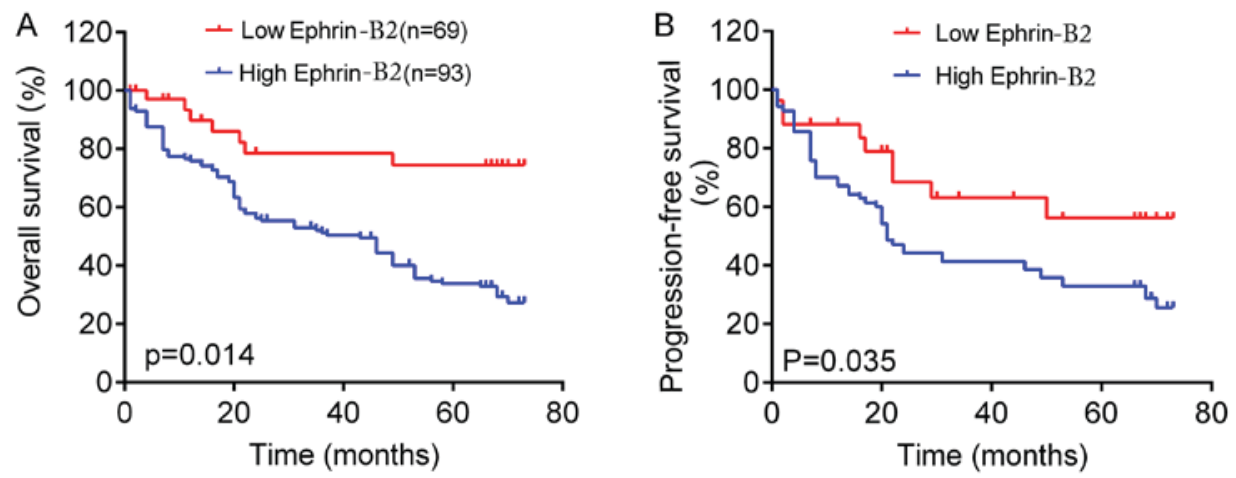

Figure 3. Kaplan-Meier survival curves for high and low protein ephrin-B2 expression level in the gastric cancer group. (A) The overall survival rate of patients with gastric cancer $(\mathrm{P}=0.014)$. (B) The progression-free survival rate of patients with gastric cancer $(\mathrm{P}=0.035)$.
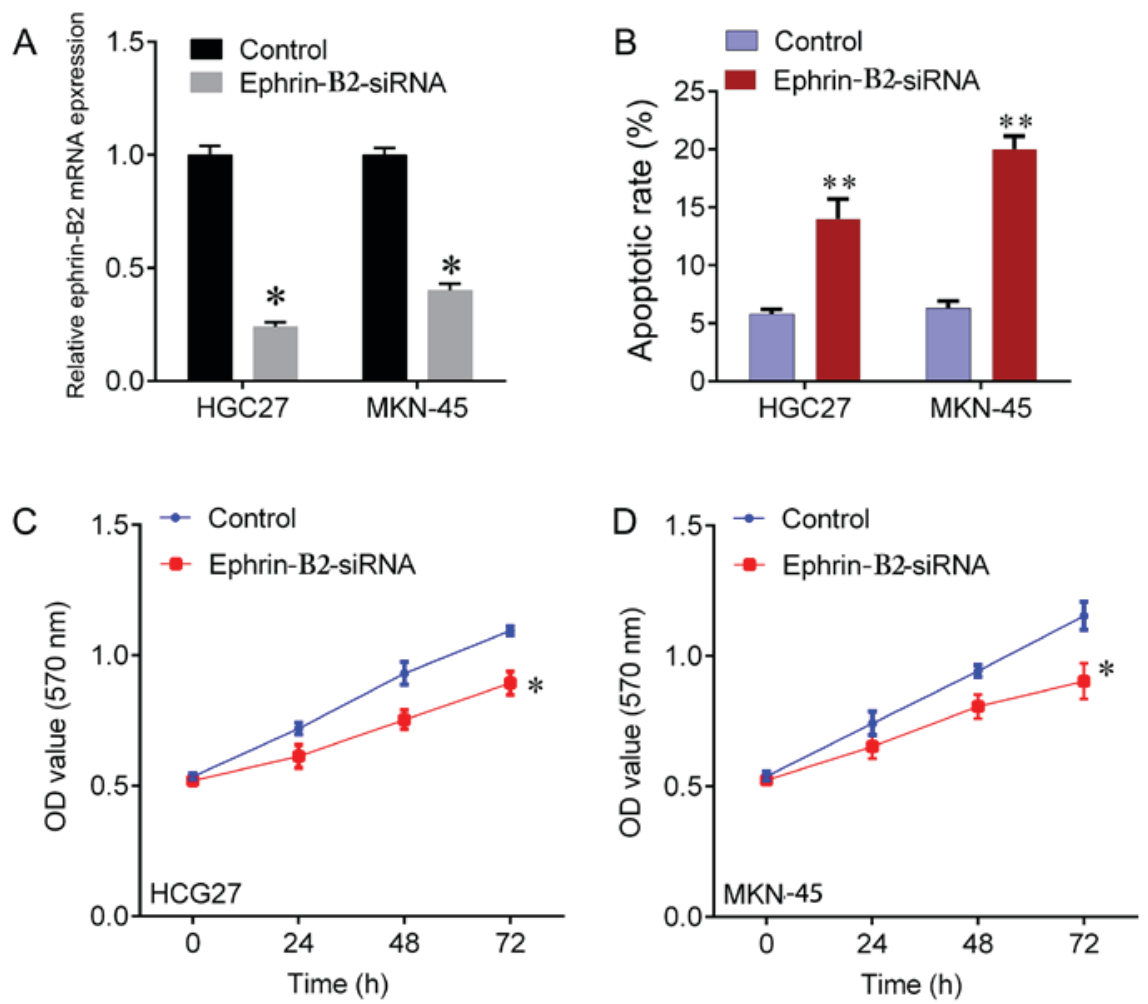

Figure 4. Effects of ephrin-B2-knockdown on apoptosis and proliferation. (A) Ephrin-B2 expression was knocked down by siRNA in HCG27 and in MKN-45 cells. (B) Apoptotic rate of HCG27 and MKN-45 cells with and without ephrin-B2-knockdown. (C) Cell viability following ephrin-B2-knockdown in HCG27 cells (D) Cell viability following ephrin-B2-knockdown in MKN45 cells. ${ }^{*} \mathrm{P}<0.05$ and ${ }^{* *} \mathrm{P}<0.001$ vs. control. siRNA, small interfering RNA; OD, optical density.

involving the c-Jun $\mathrm{N}$-terminal kinase signaling pathway and the c-Src/extracellular signal-regulated kinase pathway (17). To evaluate the function of ephrin-B2 in gastric cancer, a loss-function assay was performed in two gastric cancer cell lines. The results indicated that ephrin-B2-knockdown significantly inhibited cell viability and induced apoptosis. Thus, ephrin-B2 was demonstrated to function as an oncogene in gastric cancer. However, the underlying mechanism by which ephrin-B2 promotes gastric cancer cell proliferation requires further examination.

\section{Acknowledgements}

Not applicable.

\section{Funding}

No funding was received.

\section{Availability of data and materials}

All data generated or analysed during this study are included in this published article.

\section{Authors' contributions}

WJY and ZPC made substantial contributions to the design of the study. YPL, ML and CXL analysed and interpreted the patient data. SJM and QKL performed cell biological 
experiments. WJY and SJM performed quantitative polymerase chain reaction and immunohistochemical staining. All authors contributed to writing the manuscript. All authors read and approved the final manuscript.

\section{Ethics approval and consent to participate}

The present study was approved by the Ethics Committee of the Qianfoshan Hospital of Shandong University (Shandong, China). Written informed consent was obtained from all patients.

\section{Patient consent for publication}

All subjects participating in the present study provided written informed consent for the publication of any data.

\section{Competing interests}

The authors have no conflicts of interest to declare.

\section{References}

1. Wang Y, Nakayama M,Pitulescu ME, Schmidt TS, Bochenek ML, Sakakibara A, Adams S, Davy A, Deutsch U, Lüthi U, et al Ephrin-B2 controls VEGF-induced angiogenesis and lymphangiogenesis. Nature 465: 483-486, 2010.

2. Yavrouian EJ, Sinha UK, Rice DH, Salam MT, Gill PS and Masood R: The significance of EphB4 and EphrinB2 expression and survival in head and neck squamous cell carcinoma. Arch Otolaryngol Head Neck Surg 134: 985-991, 2008.

3. Alam SM, Fujimoto J, Jahan I, Sato E and Tamaya T: Coexpression of EphB4 and ephrinB2 in tumour advancement of ovarian cancers. Br J Cancer 98: 845-851, 2008.

4. Tu Y, He S, Fu J, Li G, Xu R, Lu H and Deng J: Expression of EphrinB2 and EphB4 in glioma tissues correlated to the progression of glioma and the prognosis of glioblastoma patients. Clin Transl Oncol 14: 214-220, 2012.

5. Zhu XL,Chen P, Guo H,Hou WJ, Shi Y, Zhang T,LiQ and Zhang N: Relationships among differentiation degree, contrast-enhanced ultrasound and the expression of Ephb4/Ephrinb2 in primary hepatocarcinoma. Hepatogastroenterology 59: 1164-1167, 2012.

6. Alam SM, Fujimoto J, Jahan I, Sato E and Tamaya T: Coexpression of EphB4 and ephrinB2 in tumor advancement of uterine cervical cancers. Gynecol Oncol 114: 84-88, 2009.
7. Krusche B, Ottone C, Clements MP, Johnstone ER, Goetsch K, Lieven H, Mota SG, Singh P, Khadayate S, Ashraf A, et al: EphrinB2 drives perivascular invasion and proliferation of glioblastoma stem-like cells. Elife 5: e14845, 2016.

8. Abengozar MA, de Frutos S, Ferreiro S, Soriano J, Perez-Martinez M, Olmeda D, Marenchino M, Canamero M, Ortega S, Megias D, et al: Blocking ephrinB2 with highly specific antibodies inhibits angiogenesis, lymphangiogenesis, and tumor growth. Blood 119: 4565-4576, 2012.

9. Li P, Chen W, Wang Y, Fu X, Wen K, Qian J, Huang C and Fu Z: Effects of ephrinB2 gene siRNA on the biological behavior of human colorectal cancer cells. Oncol Rep 33: 758-766, 2015.

10. Livak KJ and Schmittgen TD: Analysis of relative gene expression data using real-time quantitative PCR and the 2(-Delta Delta C(T)) method. Methods 25: 402-408, 2001.

11. Sharma GK, Dhillon VK, Masood R and Maceri DR: Overexpression of EphB4, EphrinB2, and epidermal growth factor receptor in papillary thyroid carcinoma: A pilot study. Head Neck 37: 964-969, 2015.

12. Ozgur E, Heidenreich A, Dagtekin O, Engelmann U and Bloch W: Distribution of EphB4 and EphrinB2 in normal and malignant urogenital tissue. Urol Oncol 29: 78-84, 2011.

13. Salvucci O, Ohnuki H, Maric D, Hou X, Li X, Yoon SO, Segarra M, Eberhart CG, Acker-Palmer A and Tosato G: EphrinB2 controls vessel pruning through STAT1-JNK3 signalling. Nat Commun 6: 6576, 2015.

14. Yamanda S, Ebihara S, Asada M, Okazaki T, Niu K, Ebihara T, Koyanagi A, Yamaguchi N, Yagita H and Arai H: Role of ephrinB2 in nonproductive angiogenesis induced by Delta-like 4 blockade. Blood 113: 3631-3639, 2009.

15. Scehnet JS, Ley EJ, Krasnoperov V, Liu R, Manchanda PK, Sjoberg E, Kostecke AP, Gupta S, Kumar SR and Gill PS: The role of Ephs, Ephrins, and growth factors in Kaposi sarcoma and implications of EphrinB2 blockade. Blood 113: 254-263, 2009.

16. Depner C, Zum BH, Bogurcu N, Cuesta AM, Aburto MR, Seidel S, Finkelmeier F, Foss F, Hofmann J, Kaulich K, et al: EphrinB2 repression through ZEB2 mediates tumour invasion and anti-angiogenic resistance. Nat Commun 7: 12329, 2016.

17. Alam SK, Yadav VK, Bajaj S, Datta A,Dutta SK, Bhattacharyya M, Bhattacharya S, Debnath S, Roy S, Boardman LA, et al: DNA damage-induced ephrin-B2 reverse signaling promotes chemoresistance and drives EMT in colorectal carcinoma harboring mutant p53. Cell Death Differ 23: 707-722, 2016.

(i) $($ This work is licensed under a Creative Commons Attribution-NonCommercial-NoDerivatives 4.0 International (CC BY-NC-ND 4.0) License. 